\title{
HUBUNGAN STRES DENGAN KELANCARAN ASI PADA IBU MENYUSUI PASCA PERSALINAN Di RSI A.YANI SURABAYA
}

\author{
Rizki Amalia \\ Fakultas Keperawatan dan Kebidanan \\ Universitas Nahdlatul Ulama Surabaya Jl. Smea No. 57 Surabaya \\ Email: amaliastikesyarsis@gmail.com
}

\begin{abstract}
The relationship stress with the smoothness of breast milk in nursing mothers postpartum. Lactation has two understanding, they are formulating / the production of breast's milk and resulting breast's milk. Many factor influence the production of ASI, one of them is stress. The purpose of the research was to know the correlation between stress with the fluency of breast's milk for breast feed's mother of post labour in RSI A.Yani. The method which was used in the research was cross sectional analytic with non random sampling (quota sampling). The Population which was used in the research were all the second days's post labour mother in RSI A.Yani And the member of samples used were 24 respondents. Collecting data by using questionnaire to know data of stress and the fluency of breast's milk. The research result was gotten to the second days's post labour mother in RSI A.Yani who experienced stress, experienced unfluency of giving breast's Milk. After data was collected then it was tabulated and it was tested by using Spearman Rank Correlation. It was obtained the result that there was the correlation between stress with the fluency of breast's milk for breast's feed's mother of post labour in RSI A.Yani. (Rho =0,628). From the research it was hoped that the second days's post labour mother could handle the emotion and psychology to think positively to be able to adapt well in their post partum periode so that the body has good response. Mothers did not experience stress and mother milk ran fluently.
\end{abstract}

Abstrak: Hubungan stress dengan kelancaran ASI pada ibu menyusui pasca persalinan. Laktasi mempunyai dua pengertian, yaitu pembentukan / produksi air susu dan pengeluaran air susu. Banyak faktor yang mempengaruhi produksi ASI diantaranya adalah stres. Tujuan penelitian ini adalah untuk mengetahui hubungan stres dengan kelancaran ASI pada ibu menyusui di RSI A.Yani. Metode yang digunakan dalam penelitian ini adalah analitik cross sectional dengan non random sampling (kuota sampling). Populasi yang dipakai dalam penelitian ini adalah semua ibu nifas hari kedua di RSI A.Yani. Dan jumlah sampel yang digunakan sebanyak 24 responden. Pengumpulan data dengan menggunakan kuesioner untuk mengetahui data tentang stres dan kelancaran ASI. Hasil penelitian didapatkan pada ibu nifas hari kedua yang mengalami stres mengalami ketidaklancaran ASI. Setelah data terkumpul kemudian di tabulasi dan diuji dengan menggunakan korelasi Spearman Rank, didapatkan hasil ada hubungan stres dengan kelancaran ASI pada ibu menyusui pasca persalinan di RSI A.Yani. (Rho $=0,628$ ). Dari penelitian ini diharapkan ibu nifas hari kedua dapat mengendalikan emosional serta psikologisnya untuk berpikir positif mampu beradaptasi dengan baik menjalani masa nifasnya sehingga tubuh berespons baik sehingga ibu tidak mengalami stres dan ASInya menjadi lancar.

Kata kunci : Stres, Kelancaran ASI 


\section{PENDAHULUAN}

Air susu ibu atau ASI merupakan sumber gizi utama bayi yang belum dapat mencerna makanan padat. ASI merupakan sumber makanan terbaik bagi bayi karena memiliki begitu banyak zat penting yang bagus guna meningkatkan kekebalan tubuh terhadap penyakit. Hasil penelitian menyatakan bahwa ASI adalah makanan bayi yang tidak ada tandingannya. Makanan bayi dan susu yang dibuat dengan teknologi masa kini tidak mampu menggantikan sumber makanan yang menakjubkan ini (Kodrat, 2010).

Produksi ASI sangat dipengaruhi oleh faktor kejiwaan (Prasetyono, 2009). Kondisi Stres pasca persalinan dialami $80 \%$ wanita setelah bersalin. Perasaan sedih atau uring-uringan yang melanda ibu timbul dalam jangka waktu dua hari sampai dua minggu pasca persalinan (Danuatmaja dan Meiliasari, 2003). Kondisi ibu yang mudah cemas dan stres dapat mengganggu laktasi sehingga dapat berpengaruh pada produksi ASI. Hal ini di karenakan stres dapat menghambat pengeluaran ASI (Kodrat, 2010). Semakin tinggi tingkat gangguan emosional, semakin sedikit rangsangan hormon prolaktin yang diberikan untuk memproduksi ASI (Prasetyono, 2009).

Sangat disayangkan bahwa di Indonesia pada kenyataannya penggunaan ASI belum seperti yang di anjurkan. Pemberian ASI yang dianjurkan adalah (a) ASI eksklusif selama 6 bulan karena ASI saja dapat memenuhi 100\% kebutuhan bayi, (b) dari 6 - 12 bulan ASI masih merupakan makanan utama bayi karena dapat memenuhi $60-70$ $\%$ kebutuhan bayi dan perlu ditambahkan makanan lumat sampai lunak sesuai dengan usia bayi, (c) diatas 12 bulan ASI saja hanya memenuhi sekitar 30\% kebutuhan bayi dan makanan padat sudah menjadi makanan utama. Saat ini usaha meningkatkan penggunaan ASI telah menjadi tujuan global. Setiap tahun pada tanggal 1-7 Agustus adalah pekan ASI sedunia (Prawiroharjo, 2008).

Hasil studi pendahuluan yang dilakukan pada tanggal 11 Januari 2015 di RSI A.Yani, dari 6 ibu nifas, 4 orang melahirkan secara SC (Secsio Cesarea) dan 2 ibu melahirkan spontan pervaginam. Satu ibu post partum hari kedua mengatakan sudah menyusui bayinya sejak hari pertama dan ASInya lancar dan 1 ibu postpartum hari kedua mengatakan belum menyusui bayinya sejak hari pertama karena ASInya belum keluar sama sekali. Dua ibu post SC hari kedua mengatakan belum menyusui bayinya sejak hari pertama karena ASInya belum keluar sama sekali dan dua ibu post SC hari pertama juga belum menyusui bayinya sama sekali karena masih berada di Ruang Pulih Sadar (Recovery Room).

Tujuan penelitian ini untuk Mengetahui pengaruh stres dengan kelancaran ASI pada ibu menyusui pasca persalinan.

\section{METODE PENELITIAN}

Penelitian ini dilakukan di Ruang Nifas RSI A.Yani Surabaya pada bulan Januari-Februari 2015. Menggunakan metode korelasi untuk mengkaji ada tidaknya hubungan stres dengan kelancaran ASI. Dalam penelitian ini menggunakan korelasi yang bersifat analitik cross sectional. Populasi yang dipakai dalam penelitian ini adalah semua ibu nifas di RSI A.Yani, Sampel yang dipakai dalam penelitian ini adalah semua ibu nifas hari kedua di RSI A.Yani. Dalam penelitian ini variabel bebasnya adalah stres. variabel terikatnya adalah kelancaran ASI. Instrumen yang digunakan dalam penelitian ini adalah kuesioner tertutup (untuk mengukur stres) yaitu suatu bentuk pertanyaan dimana responden hanya tinggal memilih atau menjawab pada jawaban yang sudah ada. Menggunakan checklist (untuk mengukur 
kelancaran ASI) yaitu jenis kuesioner yang berisi pernyataan atau pertanyaan yang akan diamati dan responden memberikan jawaban dengan memberikan cek $(\sqrt{ })$ sesuai dengan yang diinginkan (Hidayat, 2007). Untuk soal nomor 1, 2, dan 4, cara penskoran :

Jika responden memilih jawaban (a) maka skore 0 , Jika responden memilih jawaban (b) maka skore 1, Jika responden memilih jawaban (c) maka skore 2, Jika responden memilih jawaban (d) maka skore 3. Untuk soal nomor $3,5,6,7,8,9$, dan 10 , cara penskoran : Jika responden memilih jawaban (a) maka skore 3, Jika responden memilih jawaban (b) maka skore 2, Jika responden memilih jawaban (c) maka skore 1, Jika responden memilih jawaban (d) maka skore 0, Dari skore diatas, kemudian dapat dikategorikan sesuai kriteria berikut: Skore $\geq 10=$ stress Skore $<10=$ tidak stres (Childbirthsolution, 2011).

Variabel kelancaran ASI menggunakan skala Guttman, yaitu merupakan skala yang bersifat tegas dan konsisten dengan memberikan jawaban yang tegas seperti jawaban dari pertanyaan/pernyataan ya dan tidak. Apabila skor "ya" nilainya 1 dan apabila "tidak" nilainya 0 (Hidayat, 2007). Untuk menilai setiap item kuesioner dilakukan perhitungan sebagai berikut: Nilai maximum (nilai tertinggi) $=18$, Nilai minimum (nilai terendah) $=0$ Range (nilai tertinggi - nilai terendah) $=18.1-9=$ Tidak lancar. 10 -18 = Lancar

Penelitian ini variabel yang dihubungkan berskala ordinal. Data kemudian dimasukkan kedalam tabel korelasi Spearman Rank, jenis data yang dikorelasikan adalah data ordinal (Sugiyono, 2007).

\section{HASIL DAN PEMBAHASAN \\ a. Hasil}

1. Distribusi Stres ibu nifas hari kedua di RSI A.Yani, dari pengumpulan data didapatkan hasil sebagai berikut :

\begin{tabular}{cccc}
\hline No & $\begin{array}{c}\text { Kejadian } \\
\text { stres }\end{array}$ & Frekuensi & $\begin{array}{c}\text { Persentase } \\
(\%)\end{array}$ \\
\hline 1 & Ya & 15 & 62,5 \\
2 & Tidak & 9 & 37,5 \\
& Total & 24 & 100 \\
\hline
\end{tabular}

Sumber: data primer, 2015

2. Distribusi Kelancaran ASI ibu nifas hari kedua di RSI A.Yani, dari pengumpulan data didapatkan hasil sebagai berikut:

\begin{tabular}{clcc}
\hline No & Kelancaran ASI & Frekuensi & $\begin{array}{c}\text { Persentase } \\
(\%)\end{array}$ \\
\hline 1 & Lancar & 11 & 45,83 \\
2 & Tidak lancar & 13 & 54,17 \\
& Total & 24 & 100 \\
\hline
\end{tabular}

Sumber: data primer, 2015

Untuk mengetahui ada tidaknya hubungan antara stres dengan kelancaran ASI, diuji dengan uji koefisien korelasi dengan menggunakan rumus Rho Spearman, diperoleh hasil $\rho=0,628$ (Lampiran 8). Nilai Rho tersebut kemudian dikonsultasikan ke tabel dengan interval kepercayaan $95 \%$.

Dari hasil konsultasi pada tabel pada n 24 didapatkan hasil $\rho$ tabel adalah 0,409. Jadi harga $\rho$ hitung $>$ harga $\rho$ tabel $(0,628>$ 0,409), maka ada hubungan antara stres dengan kelancaran ASI, maka hipotesa diterima.

\section{b. Pembahasan}

Berdasarkan hasil yang telah diperoleh, ibu nifas hari kedua yang mengalami stres (15 responden) dipengaruhi oleh beberapa faktor diantaranya adalah ibu merasa tidak nyaman dengan keadaannya Menurut Suherni (2008), ketidaknyamanan dari perubahan fisik yang dirasakan ibu nifas hari pertama sampai kedua misalnya rasa mules karena rahim berkontraksi untuk kembali pada keadaan semula, payudara 
bengkak, nyeri luka jahitan. Rasa bersalah karena belum bisa menyusui bayinya.

Berdasarkan hasil yang diperoleh, ibu yang ASInya tidak lancar (13 responden) disebabkan oleh beberapa faktor diantaranya ibu yang kelelahan pasca melahirkan baik Secsio Cesarea maupun spontan pervaginam, ibu takut untuk mobilisasi, sehingga ibu malas untuk menyusui dan pada akhirnya ibu memilih memberikan susu formula pada bayinya.

Berdasarkan hasil perhitungan dengan menggunakan uji koefisien korelasi dengan menggunakan rumus Rho Spearman, diketahui bahwa Rho $=0,628$. Untuk mengetahui ada atau tidak hubungan antara stres dengan kelancaran ASI pada ibu menyusui dikonsultasikan ke tabel pada $n$ 24, didapatkan hasil $\rho$ tabel adalah 0,409. Jadi harga $\rho$ hitung > harga $\rho$ tabel $(0,628>$ 0,409), maka ada hubungan antara stres dengan kelancaran ASI.

Dari hasil yang di peroleh menunjukkan dari 15 responden yang mengalami stres, 11 responden ASInya tidak lancar dan 4 responden ASInya lancar. Ibu nifas hari kedua rata-rata mengalami ketidaklancaran ASI, disebabkan oleh beberapa faktor yaitu ibu yang enggan menyusui bayinya karena pada hari kedua setelah melahirkan ibu masih kelelahan, takut untuk mobilisasi, apalagi pada ibu post SC yang pada hari kedua masih terpasang infus dan kateter, merupakan faktor pemicu ketidaknyamanan dan menimbulkan stres, ibu juga cenderung memikirkan dirinya sendiri dan merasa menanggung beban berat, hal ini dapat terlihat semua yang mengurusi bayinya adalah ibu kandung pasien atau keluarganya, ibu enggan menyusui bayinya, ibu lebih memilih memberikan susu botol pada bayinya.

\section{SIMPULAN}

1. Ibu nifas hari kedua di RSI A.Yani lebih dari separo mengalami stres
2. ibu nifas hari kedua RSI A.Yani lebih dari separo di ASI nya tidak lancar

3. Ada hubungan antara stres dengan kelancaran ASI.

\section{DAFTAR PUSTAKA}

Agoes, Achdiat dkk. (2003). Teori \& Managemen Stress. Malang: Taroda.

Arikunto, S. (2006) Prosedur Penelitian Suatu Pendekatan Praktik. Jakarta: Rineka Cipta.

Azwar, Saifuddin. (2010) Penyusun Skala Psikologi. Yogyakarta. Pustaka Pelajar.

Chandra, Ely. (2007). Baby Guide. Bali: Max Media.

Childbirthsolution. (2011) Edinburgh

Postnatal Depression Scale. Diakses tanggal 28 Maret 2011. < http: www.childbirthsolution.com/ articles/ edunburgh/ postnatal/ depression/ scale >. Danuatmaja, Bonny \& Meiliasari, Mila. (2003). 40 Hari Pasca Persalinan Masalah dan Solusinya. Jakarta : Puspa Swara. Diakses tanggal 9 Februari 2011. Hasnawati dkk. (2010). Buku Profil Kesehatan 2009. Diakses tanggal 9 Februari 2011. $<$ http//www.depkes.go.id/downloads/pro filkesehatan 2009/index.html>.

Hidayat, A.Aziz Alimul. (2007). Metode Penelitian Kebidanan \& Teknik Analisis Data. Jakarta : Salemba Medika. . (2008). Pengantar

Konsep Dasar Keperawatan. Jakarta: Salemba Medika.

Huliana, Mellyna. (2003). Perawatan Ibu Pasca Melahirkan. Jakarta : Puspa Swara.

Kodrat, Laksono. (2010). Dahsyatnya ASI \& Laktasi. Yogyakarta : Media Baca.

Kristiyanasari, Weni. (2009). ASI, Menyusui \& Sadari. Yogyakarta : Nuha Medika.

Media Online. (2010). Rendah Tingkat Pemberian ASI di Indonesia. Diakses tanggal 3 Februari 2011. 
Notoatmodjo, S. (2010). Metodologi Penelitian Kesehatan. Jakarta: Rineka Cipta

Nursalam. (2008). Konsep Dan Penerapan Metodologi Penelitin Ilmu Keperawatan. Jakarta : Salemba Medika.

Prasetyono, Dwi Sunar. (2009). Buku Pintar ASI Eksklusif. Yogyakarta : Diva Press.

Prawirohardjo, Sarwono. (2008). Ilmu Kebidanan. Jakarta : Bina Pustaka Sarwono Prawirohardjo.

Proverawati, Atikah \& Rahmawati, Eni. (2010). Kapita Selekta ASI Dan Menyusui. Yogyakarta : Nuha Medika.

Roesli, Utami. (2005). Panduan Praktis Menyusui. Jakarta : Puspa Swara.

Sufnarritayusuf. (2010). Fisiologi Laktasi. Diakses tanggal 30 Maret 2011. < http ://sobatbaru.com/articles/2009/02/anat omi-payudara-dan fisiologilaktasi.html $>$.

Sugiyono. (2007). Statistika Untuk Penelitian. Bandung : Alfabeta.

Suherni dkk. (2009). Perawatan Masa Nifas. Yogyakarta : Fitramaya
Suradi, Rulina \& Roesli, Utami. (2008). Manfaat ASI dan Menyusui. Jakarta : Balai Penerbit Fakultas Kedokteran Universitas Indonesia 